\title{
Using a cessation-related outcome index to assess California's cessation progress at the population level
}

\author{
Hao Tang, ${ }^{1}$ Erin Abramsohn, ${ }^{1}$ Hye-Youn Park, ${ }^{1}$ David W Cowling, \\ Wael K Al-Delaimy ${ }^{2}$
}

${ }^{1}$ California Department of Public Health, California Tobacco Control Program, USA ${ }^{2}$ University of California, San Diego, Moores Cancer Center, Department of Family and Preventive Medicine, USA

\section{Correspondence to} Hao Tang, Genetic Disease Screening Program, California Department of Public Health, 850 Marina Bay Parkway, MS 8200, Richmond, CA 94804 USA; Hao.Tang@cdph.ca.gov

Received 15 April 2009 Accepted 4 February 2010

\section{ABSTRACT}

Background The California Tobacco Control Program (CTCP) has employed strategies to change social norms around smoking in order to decrease the prevalence of smoking and tobacco-related diseases. Research is scarce on CTCP's impact on overall smoking cessation in California

Methods Tobacco Use Supplement to the Current Population Survey (TUS-CPS) data from 1992-1993 to 2006-2007 was used to create a cessation-related outcome index (CROI), which was a summarised z score of the following determinants: plan to quit, quit attempt and recent quit rate for each of the 50 US states. CROI trends over the period of six separate TUS-CPSs were plotted for California and other comparison states, for 18-34 year olds and for those 35 years or older separately in the context of historical cigarette price $z$ score trend.

Results California had a consistently high CROI for both age groups. The CROI trend line increased moderately in California for both age groups despite a declining cigarette price $\mathrm{z}$ score trend. In contrast, other selected states with a declining cigarette price $\mathrm{z}$ score trend had a declining CROI trend for both age groups.

Conclusions The increase of CROI in California while cigarette price $z$ score trend declined suggests that the implementation of CTCP, even without a significant direct cessation component, has had a profound impact on cessation outcomes.

\section{INTRODUCTION}

In 1988, California voters approved Proposition 99 which increased the state's cigarette tax by $\$ 0.25$ and designated one-quarter of the increased revenue to the development of a comprehensive tobacco control programme including a statewide media campaign and funding to local health departments, community-based organisations, schools and agencies working with high risk populations. ${ }^{1}$ While some early antismoking programmes focused on the promotion of cessation messages and provision of behavioural interventions and services $^{2-5}$ the funding level of California Tobacco Control Program (CTCP) has prohibited the provision of equal and comprehensive cessation coverage to an estimated 4 million smokers in California. $^{6} 7$ Instead, CTCP has focused on changing social norms around smoking, primarily through policy efforts and a statewide mass media campaign to curb smoking consumption and decrease tobacco-related diseases. ${ }^{1}{ }^{8-11}$ CTCP's programme priorities include the development of policies to reduce secondhand smoke exposure, counter pro-tobacco industry influences and control the accessibility of tobacco products.

CTCP has been responsible for successfully reducing smoking in California. Previous research has attributed declines in smoking prevalence, ${ }^{12-16}$ declines in per capita cigarette consumption, ${ }^{17} 18$ and declines in tobacco-related diseases and deaths 91019 to this comprehensive tobacco control programme. Additionally, the reduced smoking prevalence rate in California relative to other states has been associated with substantial and growing reductions in per capita state healthcare expenditures. ${ }^{20}$

Declines in smoking prevalence and per capita cigarette consumption are attributed to reducing initiation (preventive effect) and increasing cessation (treatment effect). ${ }^{17} 21$ Among multiple tobacco control strategies, the effect of cigarette price on cessation behaviour (increased price can result in reduced initiation and increased cessation) has been extensively studied. ${ }^{22-25}$ Over time, all US states experienced significant increases in cigarette price, especially after the Master Settlement Agreement (MSA) in $1998 .^{26}$ In more recent years, many states have passed legislation to increase their state cigarette excise tax. However, most tobacco control programmes rarely have control over tax policies. Cigarette price has been stagnant in California since early 2000 when the vast majority of the states in the US raised their cigarette taxes. California is one of the only three states that actually saw a slight decrease in real cigarette price between 2001 and $2006 .^{26}$

In the absence of a substantial cessation treatment component and aggressive tax policies, which are not under the Program's control, CTCP has relied heavily on its social norm change strategies (including mass media and local policy efforts) to influence smokers' quitting behaviour. ${ }^{8}$ Previous research has established links between the presence of smoke-free policies and increased cessationrelated behaviour ${ }^{23} 27$; as well as relationships between the presence of mass media campaigns and smoking cessation, though the relationships were weaker and less definitive at the population level. ${ }^{24} 28$ Only a limited number of population-level studies have examined the effect of a community-focused and policy-driven tobacco control programme on direct cessation outcomes. ${ }^{1129}$

In the present study, we identified three measures of cessation behaviour from the Tobacco Use Supplement to the Current Population Survey (TUS-CPS). By combining these three measures, we compiled a cessation-related outcome index (CROI) to represent cessation behaviour rankings among 50 unlocked scheme, see http:// tobaccocontrol.bmi.com/site/ about/unlocked.xhtml 
US states. An upward CROI trend line for California would suggest that California, despite a declining standing in cigarette price relative to other states and limited focus on tobacco cessation and treatment, has made progress on cessation measures. To our knowledge, this is the first attempt to comparatively study a cessation outcome trend over a long period of time in the context of differential cigarette price changes across US states.

\section{METHODS}

\section{Adult quitting behaviour data source}

State-level data related to quitting behaviour was taken from the TUS-CPS. TUS-CPS is a national survey on tobacco use sponsored by the National Cancer Institute (NCI) and conducted by the US Census Bureau. ${ }^{30}$ The CPS surveys approximately 50 000-60000 households each month to obtain labour force information and other characteristics for household members 15 years or older. Since 1992, NCI has sponsored supplements to exclusively collect tobacco use data during certain months of the year. To date, TUS-CPS data are available for 1992-1993, 1995-1996, 1998-1999, 2001-2002, 2003 and for 2006-2007. The combined years reflect data collection for consecutive calendar years. The combined sample size ( 3 months) for each year ranges from 240000 in 2003 to almost 500000 in the 1992-1993 and 2006-2007 survey years. TUS-CPS has used a mixture of in-person surveys and telephone interviews to collect information. Although respondents sometimes provide information for other household members (proxy response), most provide information about themselves and response rates for self-respondents are over $60 \% .{ }^{31}$ To minimise the effect of population change over time and population differences between states, analyses were only conducted among nonHispanic white self-respondents aged 18 years or older. We conducted separate analyses for younger adults (18-34 years old) and older adults (35 years or older) to control for the effect of age, which has been recognised as one of the main predictors of smoking and cessation behaviour, as well as its response to price increase ${ }^{13} 223233$ TUS-CPS-recommended weights were used in the analysis to account for selection probabilities from the sampling design and adjust for survey non-response. ${ }^{31}$

\section{Measures used to construct a CROI}

After reviewing previous studies and the TUS-CPS instruments for all 6 years when surveys were conducted, we identified three variables to construct the CROI. The CROI is designed to comprehensively and comparatively reflect the overall 'quitting behaviour status' for each state (excluding the District of Columbia due to small sample size). These three variables represent direct cessation outcomes, such as quit attempt and successful quit rate, and also short-term outcomes such as establishing a quit plan. The $z$ scores were computed for each variable and represent an individual state's ranking on each cessation measure. We then took the mean of these three sets of $z$ scores as the CROI.

\section{Quit plan}

TUS-CPS asks current smokers 'are you planning to stop within the next 30 days?' A smoker's short-term quit plan has been linked to quit attempts and successful quitting. ${ }^{34-36}$

\section{Quit attempt}

A quit attempt is defined as a smoker's actual cessation action, and is believed to drive successful quitting, short term and long term. ${ }^{36-38}$ Recent studies have shown that even when quit attempts end in relapse, smokers who attempted to quit were more likely to reduce their daily cigarette consumption. ${ }^{39}$ In the TUS-CPS, current smokers were asked 'during the past 12 months, have you stopped smoking for 1 day or longer because you were trying to quit smoking?' We defined a 'yes' answer as having a quit attempt in the past year. Duration of a quit attempt and frequency of quit attempts were also considered as ideal measures for the CROI, but sample size for both of these measures were too small at the state level.

\section{Recent quit rate}

Recent quit rate (ROR) is the direct measure of cessation outcome. We defined ROR as the percentage of persons, who were daily smokers 12 months prior to the survey, who were abstinent for a minimum of 3 months. This is a commonly used measure of recent quit success in population-based studies and in clinical trials. ${ }^{40-43}$

\section{Cigarette price or price change as a confounding factor}

As noted earlier, cessation-related behaviour was found to be influenced by cigarette price. In order to control for price fluctuations over time, we plotted the $\mathrm{z}$ scores of cigarette price along with the CROI scores. Choosing a specific year's cigarette price for the analysis required serious deliberation. Most CPS survey waves had cross-year data, while tax policies in many cases were implemented at the beginning of a certain year. In addition, the price effect on cessation could occur instantly and gradually. For example, a significant increase in price could immediately trigger more quit attempts and quit plans, and may also prevent recent quitters from relapsing. At the same time, a price increase a year previously could lead to better short-term successful cessation rates (measured as abstinence for 3 or more months in a 1-year span) as well as more quit attempts and quit plans due to residual pressure from the higher price. Taking these factors into consideration, we used 3-year average or 2-year average price to plot the trend. For example, the average price for the years 1994, 1995 and 1996 was used for the 1995-1996 survey and the average price for years 2002 and 2003 was used for the 2003 survey (because all 2003 surveys were conducted within the same calendar year).

Previous studies suggest that young adults may be more sensitive to price change and may differ in cessation behaviour compared to their older counterparts. ${ }^{22} 3233$ In this study, we calculated and plotted CROI for young adults (18-34 years old) and older adults ( 35 years old or older) separately. Although the CROI trend line for California alone could indicate how California's cessation outcomes perform relative to other states due to the standardised nature of the $\mathrm{z}$ score, we plotted CROI for four groups of other states in order to gain more understanding of the CROI trend and its relationship to the cigarette price trends. Price is influential to the cessation outcome, but the presence of a sustained tobacco control programme is essential to maintain or improve cessation outcomes in absence of significant price increase.

\section{Group 1: States with a declining price rank trend}

California had a general declining trend for relative rank of cigarette price between 1992 and 2006. A total of 20 other states also had declining price rank trends during the same time period (Alabama, Arkansas, Connecticut, Delaware, Florida, Hawaii, Iowa, Louisiana, Minnesota, Mississippi, North Dakota, Nebraska, Nevada, Oklahoma, South Dakota, Tennessee, Texas, Utah, Washington and Wisconsin). These states were grouped and their CROI averages were plotted along with their average 
price rank to provide a clear picture of the general trend of CROI in the context of a declining cigarette price standing.

\section{Group 2: Florida and Minnesota}

Similar to California, Florida and Minnesota had a substantial decline in cigarette price standing (as of 2007). They were singled out from group 1 states because they also have a history of tobacco control, especially Minnesota, which was considered as the first state to have a comprehensive state tobacco control programme. However, tobacco control efforts were interrupted at times in these states. ${ }^{44-47}$

\section{Group 3: Arizona, Massachusetts and Oregon}

Similar to California, these states have a long-running tobacco control programme, with the exception that OR and MA's programmes were severely defunded around 2003. ${ }^{48} 49$ Their cigarette price standing either remained flat (Oregon) or increased (Arizona and Massachusetts).

\section{Group 4: New Jersey and New York}

New York and New Jersey participated in the ASSIST study in the 1990s. ${ }^{50}$ Similar to California, these states had high cigarette price standing at the time of the first survey (1992-1993). Unlike California, they have had a substantial increase in cigarette price $\mathrm{z}$ score trend and their cigarette prices have been consistently high. In recent years, New York has had a well funded comprehensive tobacco control programme but the results may not be apparent in the historical trend analysis.

\section{Data analysis}

For each of the three measures-quit plan, quit attempt and recent quit rate-we calculated the percentages and computed $z$ scores for each of the 50 US states in order to obtain each state's relative standing on each measure. We then took the means of these three $z$ scores for each state to form the CROI score. Repeating the procedure for each survey year allowed us to obtain state CROI score for 1992-1993, 1995-1996, 1998-1999, 2001-2002, 2003 and 2006-2007.

We used SAS V.9.1 (SAS Institute, College Station, Texas, USA) to produce point estimates (PROC MEANS and PROC FREQ procedure) and correlation analyses (PROC CORR procedure). Appropriate self-response weighting variables were used to compute the point estimates. The $\mathrm{z}$ scores were computed in Microsoft Excel 2003 (Microsoft, Redmond, Washington, USA) using the STANDARDIZE function.

Year to year cigarette price data was abstracted from The Tax Burden on Tobacco ${ }^{26}$ and entered into a Microsoft Excel spreadsheet to calculate average cigarette price over years.

We calculated average CROI scores for six surveys and plotted them to show general strength of cessation-related outcomes in a 15 -year span. We then plotted the CROI trend with simple linear regression line for young adults and older adults along with cigarette price $\mathrm{z}$ score trend using $\mathrm{R}$ language (http:// www.r-project.org/). CROI trend and cigarette price $z$ score trend were plotted for California and other groups of states.

\section{RESULTS}

\section{Average CROI scores by age group in California and other US states}

CROI scores were computed for each state for each survey year by summing the $\mathrm{z}$ scores for each CROI component. Figure 1 shows the average CROI scores for the six surveys. States were placed in groups of 10 based on their CROI scores for convenient reading purpose. During this six-survey period, California ranked fifth in CROI score (0.86) for the 18-34-year-old group and sixth (0.80) for those 35 or older.

California was also ranked high in the individual variables that form the CROI, especially the successful quitting measure. Among 50 states, California was ranked fourth in short-term successful cessation for young adults and a very close second (to Rhode Island) for the older adult group (data not shown). California was ranked 7 th and 11th in quit attempts for the young adult group and the older adult group, respectively. Regarding the plan to quit measure, California was ranked ninth and seventh for the young and older age groups, respectively.

\section{CROI trend in the context of cigarette price}

In general, for young and older adults CROI score trend lines moved up or down following the cigarette price trend line. Figure 2 shows the CROI score trend lines for California and four comparison groups of states. The group of states that had a declining price standing trend (group 1) also had a declining
Figure 1 Average CROI score in U.S. states, $1992-1993$ to 2006-2007.
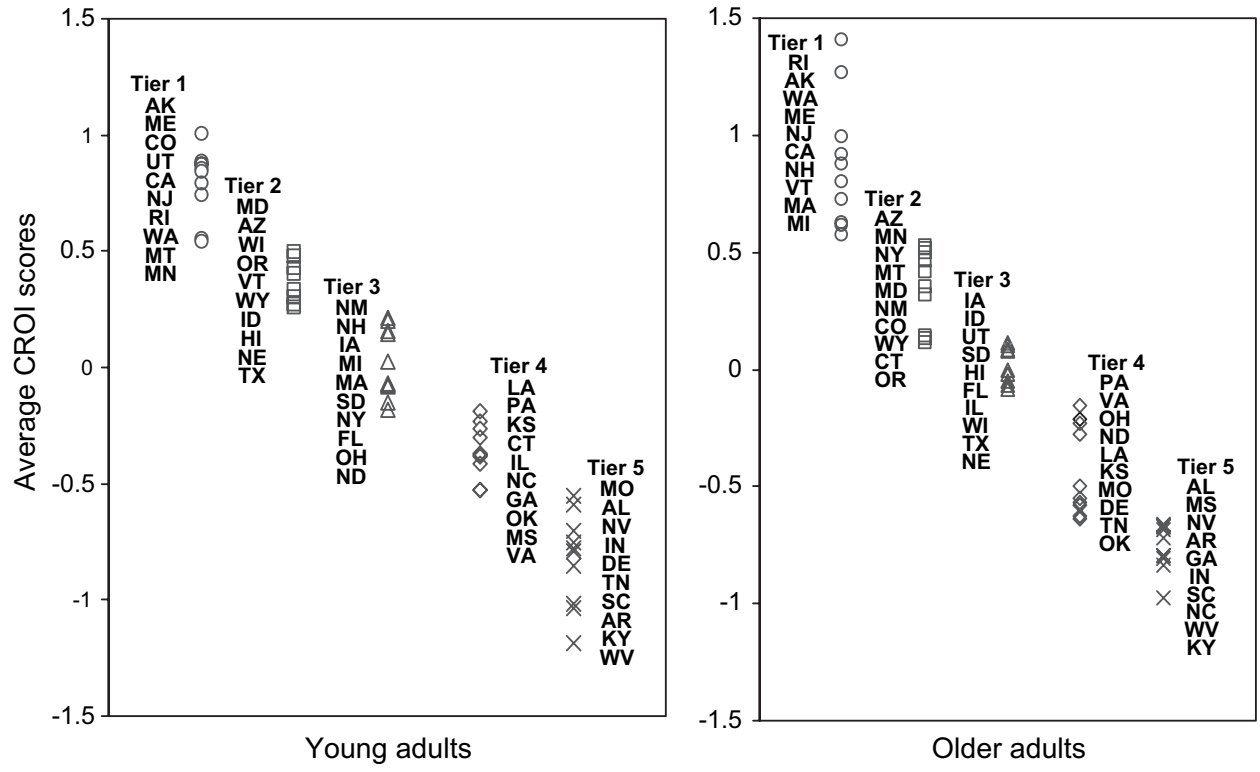
CROI trend for young and older adults. In contrast, California CROI trend lines moved moderately upward for young adults and older adults despite significant declines in cigarette price trend over the years, indicating an improvement in cessationrelated outcome standing relative to other states. California CROI standing reached its peak before the year 2000 and has remained at a relatively high level through recent years.

Florida and Minnesota experienced significant declines in price standing over the course of this study, and their CROI trends also declined. Although plotted together, individual CROI trends were similar for Florida and Minnesota (data not shown).

Arizona and Massachusetts experienced significant increases in cigarette price standing and Oregon's cigarette price standing remained relatively stable over time. Following the price trend closely, young adult CROI trended upward in these states. However, the CROI trend for older adults experienced relatively large decline. Again, although plotted using average CROI scores of these three states, the declining trend for older adults was observed in each individual state as well (data not shown).

Similar to California, New York and New Jersey had high cigarette price standing at the beginning of 1990s; but unlike California who saw their price standing drop significantly in 2000s, New York and New Jersey enjoyed consistently high and increasing cigarette price standing among US states. CROI trend for young and older adults in New York and New Jersey increased moderately over years.

\section{DISCUSSION}

As a summary ranking score for multiple measures of quitting behaviour, the CROI reflects the relative status of overall cessation outcomes for each state. The advantage of using a composite score formed from different measures of quitting behaviour instead of one single outcome, is that the final score (ranking) reflects the end cessation result (ie, quit ratio) and also different stages along the quitting continuum. Thus, the CROI is comprehensive in nature and offers a sensible measurement of cessation outcomes for evaluation and comparison purposes, increasingly important for public health professionals and policy makers at the state or national level.

Raw percentages for some CROI components, such as past year quit attempts and plan to quit within the next 3 months, saw improvements at the national level from 1992-1993 to 2007 (data not shown), which indicated healthy cessation progress in the US. In this context, the cessation progress measure (CROI) adopted in the present study shows that California ranked consistently high in cessation outcomes among the states and also had a moderate upward trend for over 15 years for young and older adult populations, indicating improved overall cessation outcomes in California relative to the rest of the US despite a substantial decrease in cigarette price standing among all the US states.

In general, states with a downward trend in cigarette price standing also saw a downward trend in CROI, which was expected based on the theory of price elasticity on cigarette demand. We observed this trend in states with limited tobacco control exposure and in states with certain level of tobacco
Figure 2 CROI score in California and other selected U.S. states, 1992-1993 to $2006-2007$.

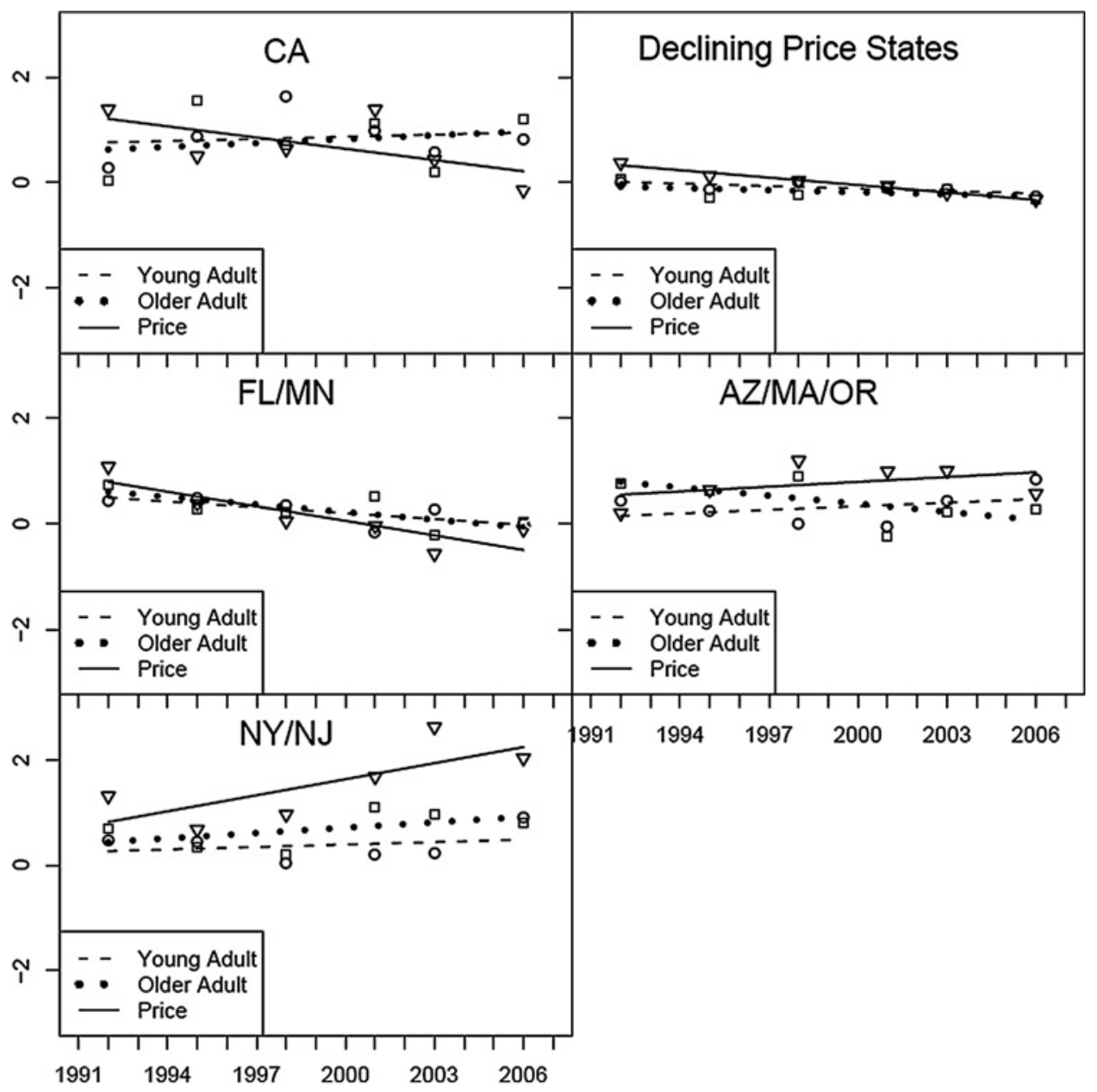


control historically. In the cases of Florida and Minnesota, both states experienced 'on-and-off' periods in tobacco control funding and programme activities due to external reasons at the state level. $^{44-47}$

Similarly, states with an upward trend in cigarette price standing were more likely to see an upward trend in CROI (data not shown). Again, we observed this trend in states with limited tobacco control exposure, in states with a history of tobacco control efforts and even among some tobacco growing states such as Kentucky. That is the case for New Jersey and New York in our analysis. Arizona, Massachusetts and Oregon showed significant improvement in young adult cessation outcome standing, but a downward trend for older adult CROI. This may be attributed to the fact that young adult cessation behaviours are considered to be more sensitive to cigarette price increases ${ }^{32} 33$; and all three states had substantial programme components targeting youth. The decreasing CROI trend seen for older adults in these states may also be attributed to the interruption of statewide tobacco control efforts.

By comparing California to the groups of selected states, we gained better understanding regarding the dynamics of the CROI trend in relation to cigarette price standing trend. Given the significant price standing decline, California's CROI would have been a declining trend similar to that of Florida, Minnesota or other states with declining price standing trends in general. Instead, the CROI trend in California resembled the slightly increasing trend seen in New York and New Jersey, where both states experienced significant cigarette price standing increases.

Our analyses demonstrate that California made progress in cessation standing in the context of declining price standing and in the absence of an extensive direct cessation service component. Although California is the pioneer regarding statewide telephone counselling to assist smokers with quitting, the capacity of the state quitline (the California Smoker's Helpline) has been limited due to budget constraints. The Helpline serves an average of 40000 smokers each year while California has an average prevalence of 4 million smokers. Providing a statesponsored nicotine replacement therapy (NRT) programme is also unrealistic due to limited funding. In other words, any progress made in cessation behaviour change would depend heavily on CTCP's social norm change strategies that combine a statewide mass media campaign with community interventions focusing on policy change. The evidence from this study suggests that a relatively sustained programme such as CTCP could indeed achieve progress or at least stability on relative cessation measures through current strategies.

Among the states presented in this study, California has the longest continuously running tobacco control programme. The longevity of the Program could contribute to California's relatively positive and stable CROI progress due to either a cohort effect or a residual effect. For example, individuals who had been exposed to tobacco control efforts for more time may be more likely to quit even after becoming smokers in later years.

Having a strong policy-oriented anti-tobacco programme does not completely protect California from the negative impacts of a drastically declining cigarette price standing. California's CROI for both age groups dropped in 2003 (before recovering in 2007) which coincided with a severe decline in cigarette price standing. A significant cigarette price increase and additional funding to strengthen cessation services could further improve California's cessation standing. ${ }^{22} 51$

Due to the relative nature of the CROI, it is important to note that a low CROI score or a decline in CROI score does not necessarily indicate 'a poor job' or a 'slowing down' regarding cessation progress, and may only suggest that cessation progress in a specific state was 'not as good' or 'not as fast' as progress observed in other states. Similarly, an increased CROI score may indicate better or faster cessation progress relative to other states.

The current analysis could be improved by obtaining a larger sample size for some states. Although the TUS-CPS is arguably the largest survey of its kind, sample sizes for some states, especially with smokers as our main analytical interest, were very small after controlling for race/ethnicity. Point estimates for states with small sample sizes would show fluctuations from year to year, introducing inconsistency into other state rankings, as well as into the overall CROI analysis. Small sample sizes also prohibit more in-depth analysis for subpopulations, such as different age and socioeconomic groups. More consistent sample sizes over time and more consistent survey instruments would greatly facilitate future analyses. In addition, the TUS-CPS questionnaire was changed moderately in 1995-1996 and again significantly in 2003, which might contribute to inconsistency across time. This study sample only included non-Hispanic white self-respondents from the TUS-CPS and provides analyses for two separate adult age groups (in order to control for the demographic shift over time and to minimise population differences among states). More detailed demographic characteristics and socioeconomic status were not included in the current studies due to sample size restrictions.

In the future, the utilities of CROI analysis could be replicated and expanded. In addition to using the TUS-CPS, future research may involve aggregated data from each state Behavioral Risk Factor Surveillance System or state-specific Adult Tobacco Surveys to perform a similar ranking.

The current study of CROI suggests that the social norm change approach employed by California, which focuses on community policy change and mass media education (instead of the widespread provision of direct cessation services that are unavailable due to funding restraints), may be responsible for improving California's overall cessation outcomes despite a significant decline of cigarette price standing. Most states and countries are currently facing an uncertain fiscal support for tobacco control. Therefore, the ability to use efficiently the limited resources that are available by promoting social norm change through policy efforts could yield an optimal return on investment.

What this paper adds

- Few population-level studies have examined the effect of a community-focused and policy-driven tobacco control programme on direct cessation outcomes.

- This study developed a composite cessation-related outcome index (CROI) that includes multiple cessation behaviour and outcome variables that can be used for trend monitoring and comparative analysis for cessation outcomes. The results showed that the CROI z score trend improved moderately in California despite decreasing cigarette price standing over the same period of time.

- This study provided evidence that the California Tobacco Control Program, although lacking a significant direct cessation component, has produced significant positive cessation outcomes at the population level. 
Acknowledgements We thank Jingyi Liu for providing technical support on data analysis. Many thanks go to Gary A Giovino and James Todd Gibson for advice and assistance with the data analysis.

\section{Competing interests None.}

Provenance and peer review Not commissioned; externally peer reviewed.

\section{REFERENCES}

1. Bal DG, Kizer KW, Gelten PG, et al. Reducing tobacco consumption in California: development of a statewide anti-tobacco use campaign. JAMA 1990:264:1570-74.

2. United Kingdom Department of Health. Health Service Circular 1999/087: new NHS smoking cessation services. London, UK: UK Department of Health, 1999. http://www. dh.gov.uk/en/Publicationsandstatistics/Lettersandcirculars/Healthservicecirculars/ DH 4004990 (accessed 12 Oct 2008).

3. COMMMIT Research Group. Community Intervention Trial for Smoking Cessation (COMMIT): summary of design and intervention. JJNCl 1991;83:1620-28.

4. National Cancer Institute. ASSIST: shaping the future of tobacco prevention and control. Tobacco Control Monograph 16. Bethesda, MD: US Department of Health and Human Services, National Institutes of Health, National Cancer Institute, 2005. http://cancercontrol.cancer.gov/tcrb/monographs/16/m16 complete.pdf laccessed 12 Oct 2009).

5. Valery L, Anke 0, Inge KK, et al. Effectiveness of smoking cessation interventions among adults: a systematic review of reviews. Eur J Cancer Prev 2008;17:535-44.

6. California Department of Public Health. California Department of Public Health celebrates 15th anniversary of the California Smokers' Helpline. http://www.cdph.ca. gov/Healthlnfo/news/Pages/PH07-22.aspx (accessed 12 Oct 2009).

7. Zhu SH, Anderson CM, Johnson CE, et al. A centralised telephone service for tobacco cessation: the California experience. Tob Control 2000;9(Suppl 2):48-55.

8. California Department of Health Services. A model for change: the California experience in tobacco control. Sacramento: California Department of Health Services, Tobacco Control Section, 1998. http://www.cdph.ca.gov/programs/tobacco/ Documents/CTCPmodelforchange1998.pdf (accessed 12 Oct 2009).

9. Fichtenberg CM, Glantz SA. Association of the California Tobacco Control Program with declines in cigarette consumption and mortality from heart disease. $N$ Engl $J$ Med 2000;343:1772-7.

10. Barnoya J, Glantz S. Association of the California tobacco control program with declines in lung cancer incidence. Cancer Causes Control 2004;15:689-95.

11. Messer K, Pierce JP, Zhu SH, et al. The California Tobacco Control Program's effect on adult smokers: (1) Smoking cessation. Tob Control 2007;16:85-90.

12. Warner KE, Mendez D, Alshanqeety 0 . Tobacco control success versus demographic destiny: examining the causes of the low smoking prevalence in California. AJPH 2008;98:268-9.

13. Pierce JP, Gilpin EA, Emery SL, et al. Has the California Tobacco Control Program reduced smoking? JAMA 1998:280:893-9.

14. Pierce JP, Gilpin EA, Emery SL, et al. Tobacco control in California: who's winning the war? An evaluation of the Tobacco Control Program 1989-1996. La Jolla, San Diego: University of California, 1998.

15. Siegel M, Mowery PD, Pechacek TP, et al. Trends in adult cigarette smoking in California compared with the rest of the United States, 1978-1994. AJPH 2000;90:372-9.

16. National Cancer Policy Board. State programs can reduce tobacco use. Washington, D.C.: Institute of Medicine, 2000

17. Gilpin EA, Messer K, White MM, et al. What contributed to the major decline in per capita cigarette consumption during California's comprehensive tobacco control programme? Tob Control 2006:15:308-16.

18. Al-Delaimy WK, Pierce JP, Messer K, et al. The California Tobacco Control Program's effect on adult smokers: (2) Daily cigarette consumption levels. Tob Control 2007;16:91-5

19. Hartman AM, Thun MJ, Ballard-Barbash R, Organizing Committee. Linking tobacco control policies and practices to early cancer endpoints: surveillance as an agent for change. Cancer Epidemiol Biomarkers Prev 2008;17:2215-19.

20. Lightwood JM, Dinno A, Glantz SA. Effect of the California tobacco control program on personal health care expenditures. PLoS Med 2008;26:e178.

21. Pierce JP, White MM, Gilpin EA. Adolescent smoking decline during California's tobacco control programme. Tob Control 2005:14:207-12.

22. U.S. Department of Health and Human Services. Reducing tobacco use: a report of the Surgeon General. Atlanta, Georgia: U.S. Department of Health and Human Services, Centers for Disease Control and Prevention, National Center for Chronic Disease Prevention and Health Promotion, Office on Smoking and Health, 2000

23. Tauras JA. Public policy and smoking cessation among young adults in the United States. Health Policy 2004:68:321-32.

24. Lemmens V, Oenema A, Knut IK, Brug J. Effectiveness of smoking cessation interventions among adults: a systematic review of reviews. Eur J Cancer Prev 2008:17:535-44.
25. Chaloupka FJ. Macro-social influences: the effects of prices and tobacco-control policies on the demand for tobacco products. Nicotine Tob Res 1999;1 (Suppl 1):105-9.

26. Orzechowski W, Walker RC. The tax burden on tobacco. historical compilation. Vo 42. Arlington, VA: Orzechowski \& Walker, 2007.

27. NIH State-of Science Panel. National Institutes of Health State-of-the-Science Conference statement: tobacco use: prevention, cessation, and control. Ann Intern Med 2006;145:839-44.

28. Bala M, Strzeszynski L, Cahill K. Mass media interventions for smoking cessation in adults. Cochrane Database Syst Rev 2008;(1):CD004704.

29. Schaap MM, Kunst $A E$, Leinsalu $M$, et al. Effect of nationwide tobacco control policies on smoking cessation in high and low educated groups in 18 European countries. Tob Control 2008;17:248-55.

30. National Cancer Institute, Cancer control and population sciences. Tobacco use supplement to the current population survey. http://riskfactor.cancer.gov/studies/tuscps/ (accessed 12 Oct 2008)

31. Census Bureau, National Cancer Institute and Centers for Disease Control and Prevention. Co-sponsored Tobacco Use Supplement to the Current Population Survey Current Population Survey, February, June, And November 2003: Tobacco Use Supplement File. Technical Documentation CPS-03. 2003. http://www.census.gov/ apsd/techdoc/cps/cpsfebjunnov03.pdf (accessed 12 Oct 2009)

32. Messer K, Trinidad DR, Al-Delaimy WK, et al. Smoking cessation rates in the United States: a comparison of young adult and older smokers. Am J Public Health 2008;98:317-22

33. Franz GA. Price effects on the smoking behaviour of adult age groups. Public Health 2008:122:1343-8

34. DiClemente CC, Prochaska J0, Fairhurst S, et al. The Process of Smoking Cessation: An Analysis of Precontemplation, Contemplation Preparation. J Consult Clin Psychol 1991;59:295-304

35. Farkas AJ, Pierce JP, Zhu SH, et al. Addiction versus stages of change models in predicting smoking cessation. Addiction 1996:91:1271-80.

36. Dijkstra A, Roijackers J, De Vries H. Smokers in four stages of readiness to change. Addict Behav 1998;23:339-50.

37. Farkas AJ, Pierce JP, Gilpin EA, et al. Is stage-of-change a useful measure of the likelihood of smoking cessation? Ann Behav Med 1996;18:79-86.

38. Macy JT, Seo DC, Chassin L, et al. Prospective predictors of long-term abstinence versus relapse among smokers who quit as young adults. Am J Public Health 2007:97:1470-5

39. Yong HH, Borland $\mathrm{R}$, Hyland $\mathrm{A}$, et al. How does a failed quit attempt among regula smokers affect their cigarette consumption? findings from the international tobacco control four-country survey (ITC-4). Nicotine Tob Res 2008;10:897-905.

40. Gilpin EA, Pierce JP, Farkas AJ. Duration of smoking abstinence and success in quitting. J Natl Cancer Inst 1997;89:572-6.

41. Giovino GA, Chaloupka FJ, Hartman AM, et al. Cigarette smoking prevalence and policies in the 50 states: an era of change-the robert wood johnson foundation impacteen tobacco chart book. Buffalo, NY: University at Buffalo, State University of New York, 2009

42. Pike KJ, Rabius V, McAlister A, et al. Prospective predictors of long-term abstinence versus relapse among smokers who quit as young adults. Am J Public Health 2007:97:1470-5.

43. Marcus BH, Lewis BA, Hogan J, et al. The efficacy of moderate-intensity exercise as an aid for smoking cessation in women: a randomized controlled trial. Nicotine Tob Res 2005:7:871-80.

44. Tsoukalas TH, Glantz SA. Development and destruction of the first state funded anti-smoking campaign in the USA. Tob Control 2003;12:214-20.

45. Ibrahim JK, Glantz SA. The rise and fall of tobacco control media campaigns, 1967 2006. Am J Public Health 2007;97:1383-96.

46. Niederdeppe J, Farrelly MC, Hersey JC, et al. Consequences of dramatic reductions in state tobacco control funds: Florida, 1998-2000. Tob Control 2008; 17:205-10

47. Tsoukalas TH, Ibrahim JK, Glantz SA Shifting tides: minnesota tobacco politics. tobacco control policy making: United States. San Francisco: Center for Tobacco Control Research and Education University of California, 2003. http://repositories. cdlib.org/ctcre/tcpmus/MN2003/ (accessed 12 Oct 2009).

48. Pizacani BA, Dent CW, Maher JE, et al. Smoking patterns in Oregon youth: effects of funding and defunding of a comprehensive state tobacco control program. $J$ Adolesc Health 2009:44:229-36.

49. Koh HK, Judge CM, Robbins $\mathrm{H}$, et al. The first decade of the massachusetts tobacco control program. Public Health Rep 2005;120:482-95.

50. Stillman FA, Hartman AM, Graubard Bl, et al. Evaluation of the American Stop Smoking Intervention Study (ASSIST): a report of outcomes. J Nat/ Cancer Inst 2003:95:1681-91.

51. Cummings KM, Fix B, Celestino P, Carlin-Menter S, et al. Reach, efficacy, and costeffectiveness of free nicotine medication giveaway programs. J Public Health Manag Pract 2006:12:37-43. 